Delft University of Technology

\title{
Bed-material transport over entrance sills at longitudinal training walls
}

van Os, W.J.; Uijttewaal, W.S.J.; Labeur, R.J.; Osorio, A.L.; Mosselman, E.; Lokin, L.R.

\author{
Publication date \\ 2020
}

Document Version

Final published version

Published in

River Flow 2020

\section{Citation (APA)}

van Os, W. J., Uijttewaal, W. S. J., Labeur, R. J., Osorio, A. L., Mosselman, E., \& Lokin, L. R. (2020). Bedmaterial transport over entrance sills at longitudinal training walls. In W. Uijttewaal, M. J. Franca, D. Valero, V. Chavarrias, C. Y. Arbos, R. Schielen, \& A. Crosato (Eds.), River Flow 2020: Proceedings of the 10th Conference on Fluvial Hydraulics (1st ed., pp. 389-395). CRC Press / Balkema - Taylor \& Francis Group. https://www.taylorfrancis.com/books/9781003110958

Important note

To cite this publication, please use the final published version (if applicable).

Please check the document version above.

\section{Copyright}

Other than for strictly personal use, it is not permitted to download, forward or distribute the text or part of it, without the consent of the author(s) and/or copyright holder(s), unless the work is under an open content license such as Creative Commons.

Takedown policy

Please contact us and provide details if you believe this document breaches copyrights.

We will remove access to the work immediately and investigate your claim. 
Green Open Access added to TU Delft Institutional Repository

'You share, we take care!' - Taverne project

https://www.openaccess.nl/en/you-share-we-take-care

Otherwise as indicated in the copyright section: the publisher is the copyright holder of this work and the author uses the Dutch legislation to make this work public. 


\title{
Bed-material transport over entrance sills at longitudinal training walls
}

\author{
W.J. van Os, W.S.J. Uijttewaal, R.J. Labeur \& A.L. Osorio \\ Delft University of Technology, Delft, The Netherlands \\ E. Mosselman \\ Delft University of Technology, Delft, The Netherlands; Deltares, Delft, The Netherlands \\ L.R. Lokin \\ HKV Consultants, Lelystad, The Netherlands; University of Twente, Enschede, The Netherlands
}

\begin{abstract}
Groynes have been replaced by longitudinal training walls in an 11-km long pilot project to optimize training of the river Waal in the Netherlands. These training walls improve navigability, reduce flood levels, create a sheltered second channel with more favourable ecological conditions, and decrease the erosive action on the river bed that is responsible for large-scale bed degradation. River managers wish to assess whether longitudinal training walls could have similar advantages along other parts of the Dutch Rhine branches (without excessive increase of maintenance costs). The required maintenance dredging depends on the amount of sediment entering the sheltered channel over an entrance sill situated at the upstream edge of the longitudinal training wall. Currently operational morphodynamic models cannot reliably compute this sediment flux. We present laboratory experiments to study the passage of bed sediment at different discharge distributions between the main and sheltered channel, and different degrees of submergence.
\end{abstract}

\section{INTRODUCTION}

Longitudinal training walls are an alternative for traditional groynes with several expected positive effects. The mild flow conditions in the sheltered channel are favourable for ecology compared to the (dynamic) flow in groyne fields (Collas et al. 2018). Groynes reduce the conveying width of the river, resulting in a larger water depth. Moreover, they increase the flow resistance and contribute to on-going bed degradation. Since longitudinal training walls are aligned with the flow, they cause less flow blockage and resistance than groynes oriented perpendicularly to the flow. Therefore, longitudinal training walls are expected to generate less bed degradation compared to groynes. A sill at the inlet of the sheltered channel is used to regulate the distribution of discharge and sediment transport. To evaluate the morphological stability of the main and sheltered channel, a numerical model is needed that can predict the morphological effect of the design of longitudinal training walls with an inlet sill. However, existing models have not been effective in predicting the sediment partitioning over the sill.

The ministry of public works, Rijkswaterstaat, initiated a pilot project with longitudinal training walls in the Waal river between Wamel and Ophemert. Huthoff et al. (2011) performed a preliminary study of hydrodynamic and morphological effects of the longitudinal training walls using Delft3D. In that study, the sheltered channel was assumed morphologically inactive, because the effect of the longitudinal training wall on sediment transport could not be implemented. Delft3D lacks a good representation of sediment transport over the inlet 
sill and the model results in the preliminary study were not in accordance with field measurements.

Delft University of Technology therefore initiated research to develop and validate a parameterisation of sediment transport at the sill for inclusion in Delft3D. To this end, Van Linge (2017) performed a hydraulic evaluation of the flow around the longitudinal training walls. He determined important mechanisms and processes based on 1D modelling. The discharge distribution towards the main and sheltered channel is mainly controlled by a different longitudinal water level slope between both channels that dependence on the different equilibrium water depth and the restricted opening of the inlet. The effect of the bending of the river on the discharge distribution is not significant. Moreover, he studied the corresponding horizontal flow patterns using depth-averaged models and he made recommendations for modelling the flow at the inlet sill in large-scale river models. Jammers (2017) developed a conceptual model that describes sediment transport trajectories over inlet sills at longitudinal training walls. He used local parameters, such as velocities of the near-bed flow, as input.

Both Van Linge (2017) and Jammers (2017) used the results of depth-averaged 2D flow models in their research. De Ruijsscher et al. (2019) performed an experimental study on the morphological effects around the longitudinal training walls. The presented results show that the angles of flow direction in front of the sill are not uniform over depth. Therefore, depthaveraged modelling requires corrections similar to the representation in such models of helical flow in river bends (cf. Rozovskii 1957). However, the vertical profile of the velocity angles at the entrance sills arises from other mechanisms such as local acceleration and sill slope. Therefore, the readily available corrections for curved flow in depth-averaged modelling are inappropriate and would have to be improved.

Designing longitudinal training walls for other locations requires an accurate and efficient model to evaluate the effects of alternative designs on the morphology. A fully threedimensional river model would be computationally demanding, although it might give more accurate results. As an alternative, we are developing a depth-averaged parameterisation of flow and sediment transport over the sill.

Previous research on the sediment transport over an inlet sill focused on the hydraulic evaluation of the flow around longitudinal training walls (Van Linge 2017), the morphology around longitudinal training walls and a theoretical description of the sediment particle trajectories (Jammers 2017). The following knowledge gaps remain:

- There are no quantitative predictors for the transport of bed load over the inlet sills at longitudinal training walls.

- Currently no validation data is available to test model concepts about the flow and sediment transport above the inlet sill.

The objective is to develop a formulation for the sediment transport over the inlet sill to the sheltered channel behind longitudinal training walls. In the end, recommendations will be given for translating this formulation into a suitable parameterisation for twodimensional depth-averaged models. This work presents preliminary findings based on the first results of laboratory experiments, namely flow fields for two experimental conditions.

\section{METHODOLOGY}

Possible input parameters for a parameterisation of sediment transport are depth-averaged flow conditions and the inlet sill dimensions of the longitudinal training walls. The discharge distribution between the main and sheltered channel and the ratio of sill height to water depth are chosen as key factors in this study. We investigate the effects of these factors in flume experiments at the Environmental Fluid Mechanics Laboratory of Delft University of Technology. 


\subsection{Experimental setup}

The experimental setup is a simplified representation of the inlet of the longitudinal training wall near Wamel in the river Waal. The experiments have been carried out in a shallow water flume made of glass. The bottom has been plated with white PVC plates. The flume is $3 \mathrm{~m}$ wide, $20 \mathrm{~m}$ long and $0.2 \mathrm{~m}$ high. Only the downstream $10.6 \mathrm{~m}$ length has been used for this experiment. The experimental setup consists of a bifurcation with a sill at the entrance of the sheltered channel. A top view is shown in Figure 1. The main channel has a width of $1.85 \mathrm{~m}$. The other half of the flume consists of three areas. Upstream there is a zero-discharge zone separated by a wooden plate. Then there is an inlet area with a length of $2.66 \mathrm{~m}$. Downstream of the inlet, the third zone, is the sheltered channel separated from the main channel by a vertical plate that represents the training wall. The width of the sheltered channel is $1.13 \mathrm{~m}$. The sill is located at the entrance of the sheltered channel and has a height of $51.5 \mathrm{~mm}$, a slope of $1: 2.5$ and a $27 \mathrm{~mm}$ wide crest. The geometry of the sill is extended over the entire length of the experimental setup to reduce secondary flow effects. A side view is shown in Figure 2.

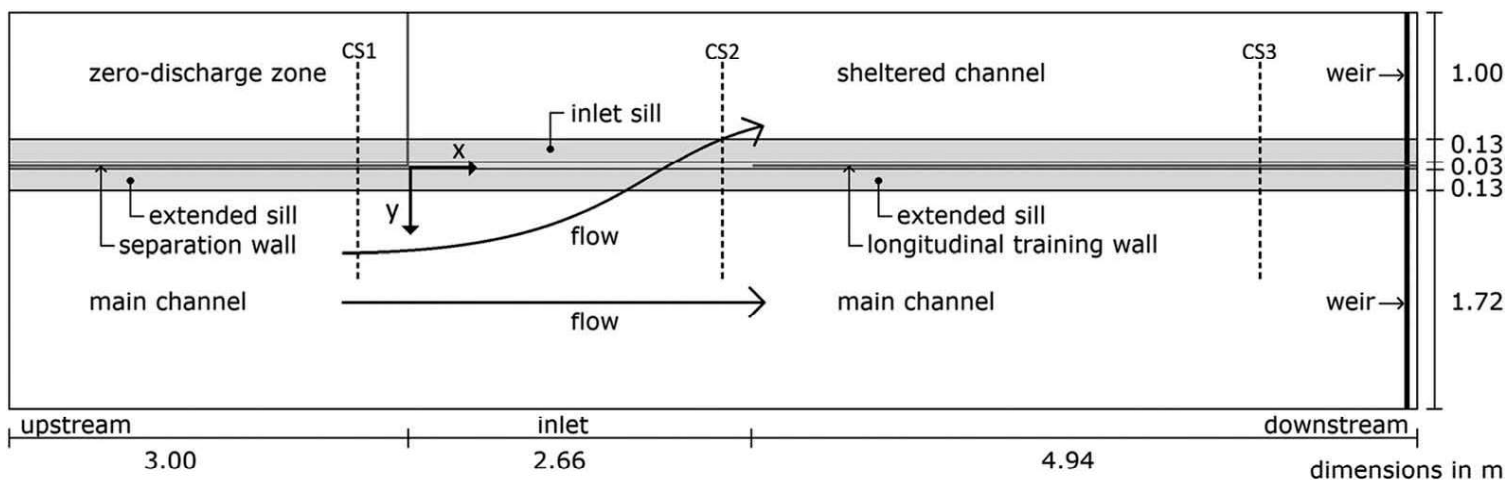

Figure 1. Top view of the experimental setup where the blue arrow indicates the flow direction, the grey area represents the sill, the blue lines are the training walls and the green lines represent the downstream weirs. The cross-sectional locations are drawn in grey and indicated with CS1, CS2 and CS3.

Cross section 1

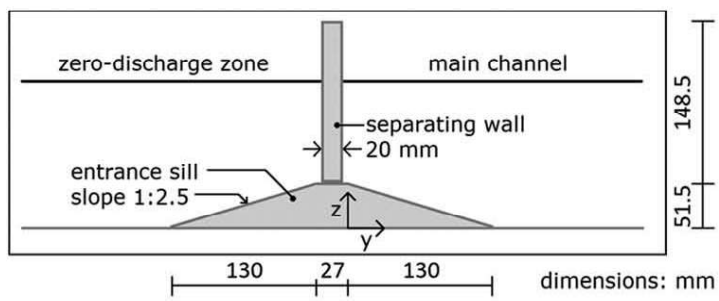

Cross section 2

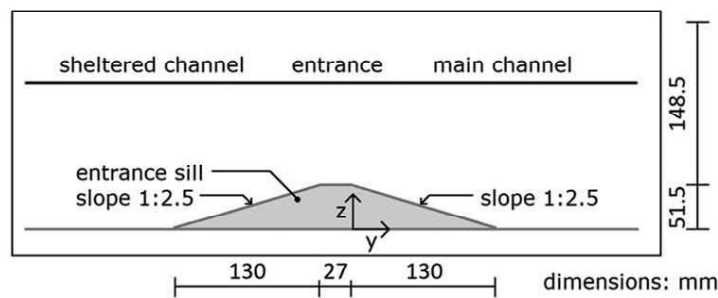

Cross section 3

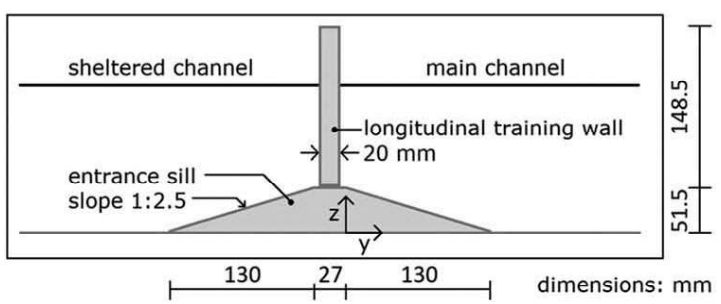

Figure 2. Cross sections of the inlet sill in the experimental setup upstream (1), at the entrance (2) and downstream (3) and a cross section with the locations for point measurements at the upstream side of the sill. 
The discharge from a constant head tank is set by a valve. At the downstream end, two replaceable weirs are present to regulate the discharge distribution and water depths in the main channel and the sheltered channel. Downstream of the flume, water flows back to the central basin of the laboratory.

\subsection{Experimental conditions}

The studied dimensionless parameters are 1) the ratio of the inlet sill height to the water depth above the crest of the sill and 2) the ratio of the discharge through the sheltered channel to the discharge through the main channel. These parameters have been varied by adapting the downstream weir heights, while keeping the total discharge of $35 \mathrm{l} / \mathrm{s}$ constant. The experimental condition was defined based on the weir height combinations. Experimental setups indicated by the character A correspond to low downstream weir heights (less than or equal to $80 \mathrm{~mm}$ ). B denotes setups, on the other hand, having large weir heights (greater than or equal to $120 \mathrm{~mm}$ ). The weir heights are equal for cases 1, the weir height in the main channel is smaller than in the sheltered channel in cases 2 and vice versa in case 3 . The experimental conditions are shown in Table 1. The difference in large and small weir heights (indicated as A and B) results in a significant difference in the water depth above the sill crest. This can be coupled to the dimensionless ratio of sill height to water depth. Variation of the weir heights in the main and sheltered channel (indicated as 1 and 2) results in different discharge distributions towards the main and sheltered channels. In Table 1, the discharge distribution is expressed in terms of the specific discharges, where the specific discharge, $\mathrm{q}$, is the discharge divided by the channel width.

\subsection{Measurements}

Data related to depth-averaged flow and flow near the bottom in which flow patterns can be identified are necessary. We assume the velocity at mid-depth to be representative for the depth-averaged flow and hence similar to depth-averaged model results. Besides, the flow near the bottom is the driving force for bed-load transport. Point measurements are performed at mid-depth using Acoustic Doppler Velocimetry (ADV, Nortek Vectrino) at $25 \mathrm{~Hz}$ for 180 seconds. To gain more insight into the horizontal flow patterns, flow field measurements are performed with Particle Image Velocimetry (PIV) using floating polypropylene particles of $3 \mathrm{~mm}$ diameter. The horizontal flow patterns near the bed are studied with heavier tracer particles and Particle Tracking Velocimetry (PTV). The latter particles have a diameter of $6 \mathrm{~mm}$ and a density of $1050 \mathrm{~kg} / \mathrm{m}^{3}$. Therefore, they just sink and roll over the bottom. Due to the submerged weight, the particles will contain momentum and behave slightly differently than water. Therefore, some additional point measurements with ADV are done near the bed.

Particles that pass the crest of the sill are not expected to return. Therefore, the locations of the point measurements are chosen upstream of the inlet sill, above the upward slope and the crest of the sill, and not downstream of the sill. Flow angles and transverse velocities are

Table 1. Experimental conditions with variation in the dimensionless parameters: the discharge distribution, expressed in the specific discharges of the main and sheltered channel $\left(\mathrm{q}_{\mathrm{m}} / \mathrm{q}_{\mathrm{s}}\right)$, and the ratio of the sill height to the water depth above the sill crest (w/d). These conditions are achieved by adapting the downstream weir heights of the main and sheltered channel.

\begin{tabular}{lllll}
\hline $\begin{array}{l}\text { Name of } \\
\text { experiment }\end{array}$ & $\begin{array}{l}\text { Discharge } \\
\text { distribution } \\
(-)\end{array}$ & $\begin{array}{l}\text { Sill height to } \\
\text { water depth ratio } \\
(-)\end{array}$ & $\begin{array}{l}\text { Main channel } \\
\text { weir height } \\
(\mathrm{mm})\end{array}$ & $\begin{array}{l}\text { Sheltered channel } \\
\text { weir height } \\
(\mathrm{mm})\end{array}$ \\
\hline A1 & $\mathrm{q}_{\mathrm{m}} \approx \mathrm{q}_{\mathrm{s}}$ & $\mathrm{w} / \mathrm{d} \approx 1.0$ & 80 & 80 \\
$\mathrm{~A} 2$ & $\mathrm{q}_{\mathrm{m}}>\mathrm{q}_{\mathrm{s}}$ & $\mathrm{w} / \mathrm{d} \approx 1.0$ & 60 & 80 \\
$\mathrm{~A} 3$ & $\mathrm{q}_{\mathrm{m}}<\mathrm{q}_{\mathrm{s}}$ & $\mathrm{w} / \mathrm{d} \approx 1.0$ & 80 & 60 \\
B1 & $\mathrm{q}_{\mathrm{m}} \approx \mathrm{q}_{\mathrm{s}}$ & $\mathrm{w} / \mathrm{d} \approx 0.5$ & 160 & 160 \\
B2 & $\mathrm{q}_{\mathrm{m}}>\mathrm{q}_{\mathrm{s}}$ & w/d $\approx 0.5$ & 120 & 160 \\
\hline
\end{tabular}


Top view - locations point measurements and edge video frames

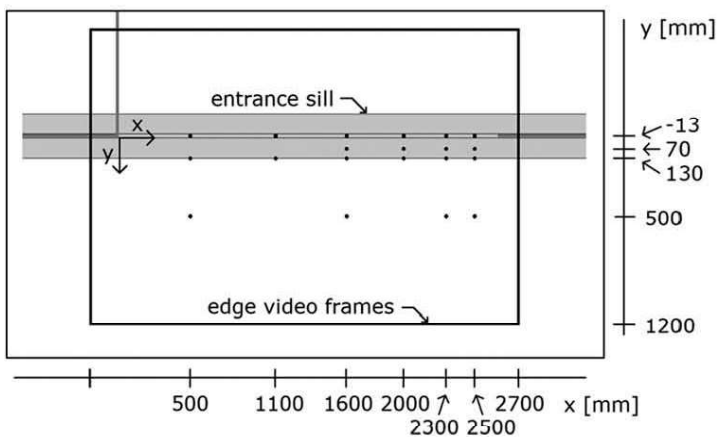

Cross section 2 - locations point measurements at mid-depth

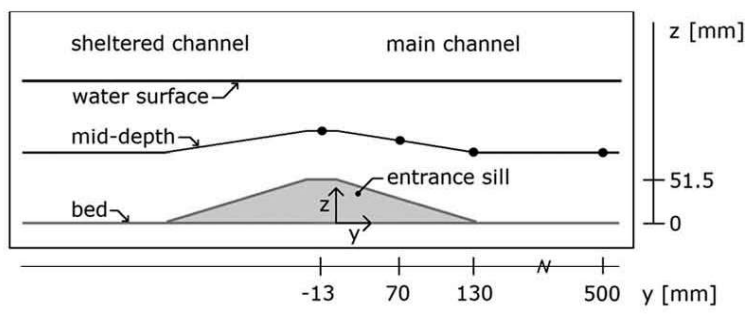

Figure 3. Locations of point measurements and the area of flow field measurements. The locations for point measurements are in front of and above the upward slope and crest of the sill with increasing density in downstream direction. The area of the flow field measurements depends on the video frames. The area of the video frames is in the middle of width the flume and covers the entire entrance sill area.

expected to increase along the slope in downstream direction based on the results by Van Linge (2017) and De Ruijsscher et al. (2018). To identify the flow patterns accurately and efficiently, the density of the measurement locations increases in the downstream direction, see Figure 3.

\section{PRELIMINARY RESULTS}

Preliminary results of cases A1 and A3 are presented in this section. Flow fields at the water surface and near the bottom are shown in Figure 4 and Figure 5 respectively. The downstream weir in the sheltered channel is lower in case A3 than in case A1. This results, as intended, in larger flow towards the sheltered channel in case A3. The transverse velocity above the sill increases in downstream direction for both cases, at the water surface as well as near the bottom. This increase is approximately 1.5 to 2 times stronger for case A3 than case A1. Larger transverse velocities near the bottom result in a larger transport capacity over the sill, if there is any bed load being transported over the sill. Albeit based on two conditions only, the results suggest that a larger relative discharge towards the sheltered channel results in a larger sediment transport capacity towards the sheltered channel. Also, this effect seems to increase in downstream direction over the inlet.
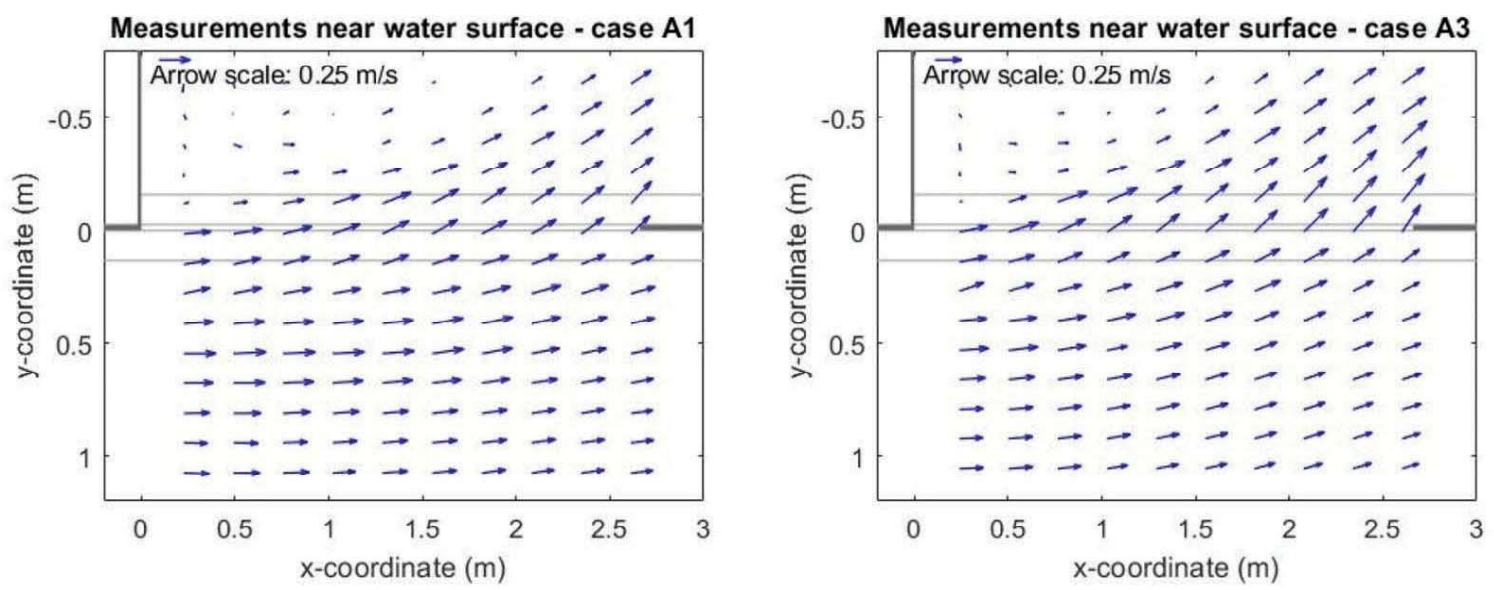

Figure 4. Velocity vectors of the measurements near the water surface. The lower channel is the main channel and the upper channel is the channel sheltered by the longitudinal training wall indicated by the thick line at the right). At the entrance a sill is present, drawn with thin lines. The scaling is indicated by an arrow representing $0.25 \mathrm{~m} / \mathrm{s}$. 

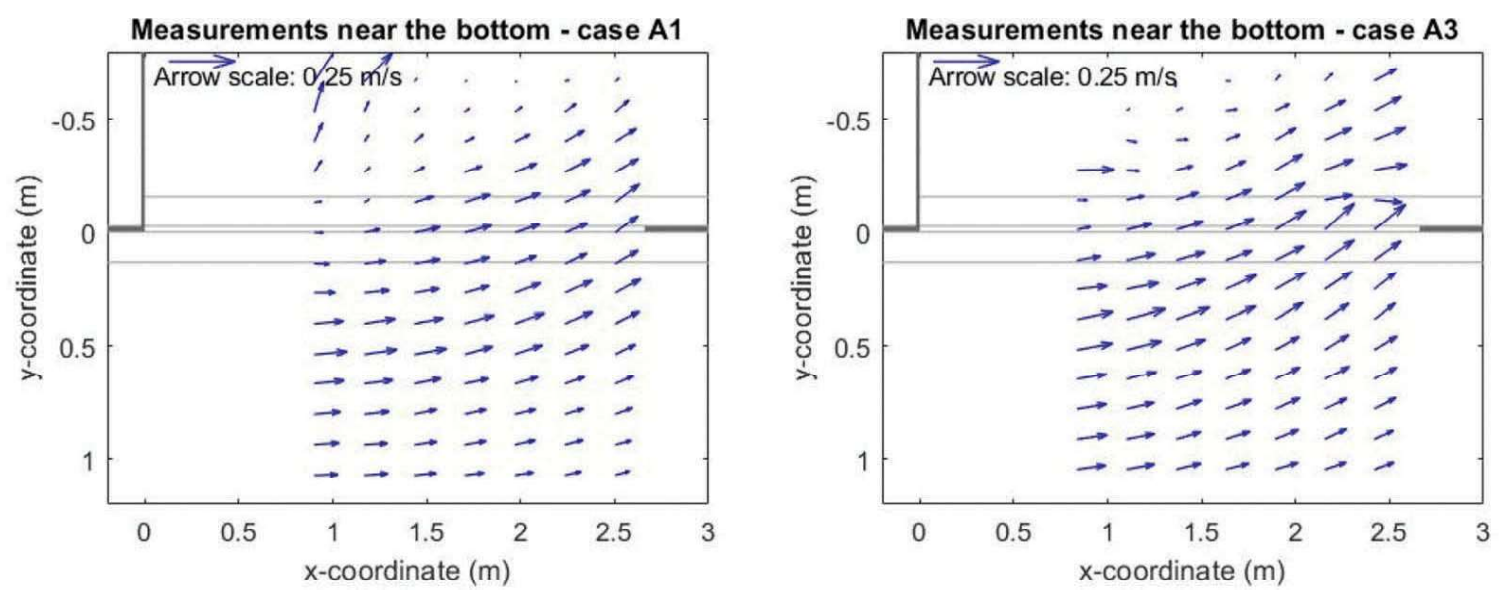

Figure 5. Velocity vectors of the measurements near the bottom. The lower channel is the main channel and the upper channel is the channel sheltered by the longitudinal training wall indicated by the thick line at the right. At the entrance a sill is present, drawn with thin lines. The scaling is indicated by an arrow representing $0.25 \mathrm{~m} / \mathrm{s}$.

Due to the larger density of sediments compared to the used tracer particles, the resulting gravity force is larger and hence sediment transport is expected to be directed less towards the sheltered channel. A flow that is strong enough to transport a particle uphill does not guarantee passage, because the particles also need to reach the crest. If the angle of the sediment transport with respect to the longitudinal direction is smaller than the flow angle, the distance a particle has to travel to reach the sill crest is larger. Therefore, the length over which the transverse component of the flow velocity is strong enough to transport a particle up-hill might be a limiting parameter for bed-load transport over the sill. The flow angles at the sill are smaller for the measurements near the bottom compared to the measurements near the water surface, see Figure 4 and Figure 5. In addition, the flow towards the sheltered channel is concentrated relatively more downstream of the inlet, hence the effective sill length for reaching the crest might be smaller. Therefore, the three-dimensional processes, which create the differences in flow patterns between the surface and bottom, might have a limiting effect on sediment transport towards the sheltered channel.

\section{CONCLUSIONS}

The preliminary results suggest that a larger relative discharge towards the sheltered channel results in a larger sediment transport towards the sheltered channel and this effect increases in downstream direction over the inlet. In addition, three-dimensional processes seem to have a limiting effect on sediment transport towards the sheltered channel. We continue our experimental programme after submission of this paper. We expect to present a more complete picture of our findings on bed-material transport over inlet sills at longitudinal training walls, along with a first set-up of the parameterization to be implemented in a two-dimensional depth-averaged model.

\section{REFERENCES}

Collas, F. P. L., Buijse, A. D., Van den Heuvel, L., Van Kessel, N., Schoor, M. M., Eerden, H. \& Leuven, R. S. E. W. 2018. Longitudinal training dams mitigate effects of shipping on environmental conditions and fish density in the littoral zones of the river Rhine. Science of The Total Environment, 619-620, 1183-1193.

De Ruijsscher, T. V., Hoitink, A. J. F., Naqshband, S. \& Paarlberg, A. J. 2019. Bed morphodynamics at the intake of a side channel controlled by sill geometry. Advances in Water Resources, 134. 
De Ruijsscher, T. V., Naqshband, S. \& Hoitink, T. 2018. Flow Bifurcation at a Longitudinal Training Dam: Effects on Local Morphology. In: A. Paquir, N. R. (ed.), 9th International Conference on Fluvial Hydraulics, River Flow 2018. Lyon-Villeurbanne; France: EDP Sciences.

Hutho, F., Paarlberg, A., Barneveld, H. \& Van der Wal, M. 2011. Rivierkundig onderzoek WaalSamen. Lelystad: HKV Lijn in Water.

Jammers, S. M. M. 2017. Sediment transport over sills of longitudinal training dams. Thesis (MSc), Delft University of Technology, National University of Singapore.

Rozovskii, I. L. 1957. Flow of water in bends of open channels, Kiev, Academy of Science of the Ukrainian SSR.

Van Linge, B. W. 2017. Hydraulic evaluation of longitudinal training dams. Thesis (MSc), Delft University of Technology. 